\title{
Resource-based competition: Three schools of thought and thirteen criticisms.
}

\author{
Tarek El Shafeey and Paul Trott \\ University of Portsmouth.
}

\section{Purpose}

The field of research on resource based competition is full of nuanced terminology and misunderstandings (Lockett et al., 2009). This has led to confusion thus we offer a critical review, which provides a structure and clarity to this subject.

\section{Design/Methodology}

This analysis structures the literature on resources, capabilities, and competences into three distinct schools of thought: (1) the resource-based view of the firm (RBV), the rational-equilibrium school; (2) the dynamic capability-based view of the firm, the behavioural-evolutionary school; and (3) the competence-based view of the firm, the social constructionist school.

\section{Findings}

We uncover thirteen criticisms of the most widely adopted theoretical framework of the RBV of the firm- VRIO -Valuable-Rare-Imperfectly imitable- Organisation- (Barney and Clark (2007).

\section{Research Limitations/implications}

The misinterpretation and neglect of the classic scholary work (e.g., Penrose (1959) and Dierickx and Cool (1989a)) may help to explain why the VRIO framework has been elevated from a view to a theory and why it has receievd so much attention.

\section{Practical implications}

We show how the relative ease of measuring resources as compared to (dynamic) capabilities and (core) competencies has helped raise the profile of RBV.

\section{Social implications}

The "management-fashion-setting process" may explain why RBV has been elevated from a view to theory (Abrahamson, 1996).

\section{Originality/value}

This analysis contributes to management research by illustrating the deviation among the three schools of thought; we show how this has contributed to wide terminological confusion and offer a structure to help researchers situate their work within the relevant school of thought. 


\section{Introduction}

Why do some firms persistently outperform others? To answer this central question, two competing paradigms dominate strategic management thinking: the External Factors Paradigm; and the Internal Factors Paradigm. The former appears to share the view that rents flow from privileged product market positions (the exploitation of market power). As a result, approaches in this paradigm (e.g., the competitive forces approach developed by Porter $\left.(1980)^{1}\right)$ tend to focus on product market imperfections, entry deterrence, and strategic interaction. The latter, also known as the resource-based view of the (henceforth the RBV), contends that the main sources of competitive advantage are proactively created and maintained by firms through acquiring and/or accumulating their strategic resources. As a result, the central question actually now becomes: Of all the resources currently controlled by a firm, which are most likely to be a source of competitive advantage (Barney and Clark, 2007; Black and Boal, 1994; Collis and Montgomery, 1995; Hunt and Derozier, 2004; Priem and Butler, 2001a; Teece et al., 1997; Wernerfelt, 1984).

The resource-based view of the firm is a stream of research that also encompasses several important explanations of persistent performance differences, namely that of the resourcebased view (RBV) of the firm (e.g., Barney, 1991, 1995; Barney and Clark, 2007; Wernerfelt, 1984), the dynamic capability (DC) based view of the firm (e.g., Teece, et al., 1997; Winter, 2003), and the (core) competence-based view (CBV) of the firm (e.g., Hamel and Heene, 1994; Prahalad and Hamel, 1990; Sanchez and Heene, 2004; Sanchez and Heene, 1997b; Sanchez et al., 1996b).

The field of research on resource based competition is full of nuanced terminology and misunderstandings. Of course, this partly reflects the intense interest and lively debate within 
the management research community, but it does nonetheless present difficulties for scholars attempting to begin research in the field. Furthermore, we also recognise that within this paradigm there exists a dominant theoretical framework- VIRO that deserves attention. Our intention is not to provide an exhaustive interpretation of all papers that have been written about the RBV; rather, the purpose of this paper is to advance our understanding of this stream of research by structuring the literature into three distinct schools of thought and to use this as a lens to critically discuss the most widely adopted theoretical framework in this line of research, the VIRO. This analysis contributes to management research by illustrating the deviation among the three schools of thought and this helps to explain some of the criticisms that have emerged. We show how this has contributed to wide terminological confusion and offer a structure to help researchers situate their work within the relevant school of thought. Significantly, this paper contributes to the debate on fundamental conceptual and theoretical criticisms of VRIO (Sanchez, 2008) and argue that it does not adequately address the notion of resource-based competition, and its claim to be a general view of resources is unwarranted theoretically and unsupported empirically.

\section{The resource-based Views : One paradigm, but three schools of thought}

The resource-based view of the firm is a line of research that also encompasses several important explanations of persistent performance differences, namely that of the resourcebased view (RBV) of the firm (e.g., Barney, 1991, 1995; Barney and Clark, 2007; Wernerfelt, 1984), the dynamic capability (DC) based view of the firm (Ambrosini and Bowman, 2009; e.g., Teece, et al., 1997; Wang and Ahmed, 2007; Winter, 2003) and the (core) competencebased view (CBV) of the firm (e.g., Hamel and Heene, 1994; Prahalad and Hamel, 1990; Sanchez and Heene, 2004; Sanchez and Heene, 1997b; Sanchez, et al., 1996b). 
Some scholars consider the three views to be one school of thought that share the same underlying theoretical structure. For example, Barney and Clark (2007) suggest that there seems to be a battle of the label of this common theoretical framework. They go on to argue that while these theories have a slightly different way of characterizing firm attributes they share the same underlying theoretical structure. They state that:

In this sense, resource-based theory is not really about resources, per se, but about the attributes that resources must possess if they are to be a source of sustained competitive advantage. [emphasis added] (Barney and Clark, 2007: 249-250).

In this context, Newbert (2007) classifies this line of research into: (1) the "early incarnations of the RBV" (e.g., Barney, 1991); and (2) the "more contemporary theoretical extensions" (e.g., Prahalad and Hamel, 1990; Teece, et al., 1997).

Others consider these views to be two distinct schools of thought. For example, Makadok (2001) identifies two rent creation mechanisms: (1) the "resource-picking mechanism" which adopts the "Ricardian perspective", and has been codified into "a resource-based view" (e.g., Barney, 1986; Wernerfelt, 1984); and the "capability-building mechanism" which adopts the "Schumpeterian perspective", and has been codified into "a dynamic-capability view" (e.g., Dierickx and Cool, 1989a; Nelson and Winter, 1982; Teece, et al., 1997). He argues that, in some cases, these two mechanisms "complement each other"; in other cases however, they "substitute each other".

The others consider these views to be three distinct schools of thought. Seoudi (2009) is an interesting example. Based on a "thorough analysis" of the underlying philosophical and epistemological foundations and the fundamental assumptions employed by the key scholars of the resource-, dynamic capability-, and competence-based views, she classifies this line of 
research into three schools: "the rational-equilibrium school (the RBV); behavioralevolutionary school (the DC); and the social constructionist school (the CBV)". She argues that although each school represents a "unique frame of lens", some authors equate the RBV with all three schools. In addition, very often, scholars consider the dynamic capability- and competence-based views to be "one research program while attributing the differences to mere semantic preferences and a proliferation of terms that in many cases refer to the same phenomena". Though, they are "three distinct schools, which exhibit some similarities, but also house non-trivial differences".

In this paper, we adopt the position that these three views are three distinct schools of thoughts. Table 1 outlines a metatheoretical scheme for classifying the major schools of thought within the resource-based paradigm. We use this classification to address the notion of resource based competition and examine the most widely adopted theoretical framework in this stream of research- the VRIO framework.

[Insert Table 1 here]

\section{The RBV of the firm and the VRIO framework}

The RBV of the firm is one of the most widely accepted views within strategic management, and "the number of proponents who have elevated it from the status of 'view to theory' is growing" (Priem and Butler, 2001a; Sanchez, 2008). It does not only serve as "a major theoretical foundation in the scholarly literature ..., but, it is also prominently featured in all major textbooks on the subject of strategic management, research, teaching, and consulting agendas" (Newbert, 2007). Furthermore, a number of significant studies (Lippman and

Rumelt, 1982; Rumelt, (1984) Wernerfelt, 1984; ${ }^{3}$ Barney, 1986; ${ }^{4}$ Barney, (1991) Rumelt, 
(1991) and Barney, (1995), among others) have developed the foundation of what has become known as the resource-based theory (RBT) of the firm. Table 2 summarizes the foundational building blocks of this body of theory.

[Insert Table 2 here]

\section{A theoretical framework}

The work of Barney (1991, 1995), Barney and Arikan (2001), and Barney and Clark (2007) provide a theoretical framework of the RBV of the firm. This has four key elements: i) assumptions; ii) firm resources; iii) attributes of strategic resources; and iv) the path to sustained competitive advantage.

\section{i) Assumptions}

Barney argues that, in order to understand the sources of sustained competitive advantage, the model should begin with two assumptions: firm resources may be heterogeneous and immobile. In the former, “building on Penrose [(1959)]'s work, this work assumes that firms can be thought of as bundles of productive resources, and that different firms possess different bundles of these resources". In the latter, "drawing on the work of Selznick and Ricardo, this approach assumes that some of these resources are either very costly to copy or inelastic in supply" (Barney, 2007: 133). These assumptions contrast with the earlier theories of the firm that view it as a homogeneous bundle of tangible productive resources that lies outside the firm.

\section{ii) Firm resources}


According to the RBV, a firm is an integrated set of tangible and intangible resources controlled by the firm that enables it to conceive of and implement strategies designed to improve its efficiency and effectiveness. Here, the tangibility of firm resources is a matter of degree. Resources that are typically more tangible include, but are not limited to, financial capital resources: e.g., equity capital, and debt capital; and physical capital resources: e.g., the geographic location, plants and equipment, and the physical technology. Resources that are typically less tangible include, but are not limited to, human capital resources: e.g., training, experience, judgment, intelligence, and insights of single individuals; and organizational capital resources: e.g., firm's cultural, its formal reporting structure, formal and informal planning, controlling and coordinating systems, and informal relations among groups within the firm and between the firm and those in its environment (Barney and Clark, 2007).

\section{iii) Attributes of strategic resources}

Barney and Clark (2007) argue that since different types of resources can have different competitive effects for firms, not all firm resources hold the potential of sustained competitive advantage. In this respect, to have this potential, a firm resource must have four attributes: valuable $(\mathrm{V})$, rare $(\mathrm{R})$, imperfectly imitable $(\mathrm{I})$, and organization $(\mathrm{O})$, known as the VRIO framework. Here is their argument.

First, it must be valuable. A valuable resource enables a firm to implement a strategy that has the effect of exploiting environmental opportunities or neutralizing threats by: (a) lowering the firm's net cost and/or increasing the firm's net revenues beyond would have been the case if this valuable resource had not been used; and/or (b) increasing the willingness of its 
customers to pay ${ }^{5}$. Exploiting this valuable resource increases the economic value the firm creates (Barney, 1991; Barney and Arikan, 2001; Barney and Clark, 2007).

Second, it must be rare. The rare resource is not simultaneously possessed by large numbers of other current or potential rivals. This may be due to the physical rareness in the strategic factor market (SFM) and/or rivals cannot perceive its value due to the firm's particular resource combination (Barney, 1991; Barney and Arikan, 2001; Barney and Clark, 2007).

Third, it must be imperfectly imitable. An imperfectly imitable resource is a firm's resource that competitors cannot directly duplicate. In other words, competitors without this resource face a "cost disadvantage" in acquiring or developing it. In this respect, a resource can be imperfectly imitable for one or a combination of three reasons: (1) accumulating this resource is dependent upon unique historical conditions (history-based or path-dependent); (2) it is socially complex; and/or (3) the link between this resource and the firm's superior performance is causally ambiguous. Here, the causally ambiguous relationship may be due to one or more of the following reasons: (a) resources and capabilities are "taken-for-granted" organizational characteristics or "invisible assets"; (b) managers are unable to evaluate which of their resources and capabilities, alone or in combination, actually create the sustained competitive advantage; and/or (c) these resources and capabilities may follow the notion of interconnectedness and asset mass efficiencies introduced by Dierickx and Cool (1989a). However, the previous three reasons work under the "nonsubstitutability" assumption which means that firms, which cannot imitate the valuable and rare resource, cannot use different resource to implement the same strategy (Barney, 1991; Barney and Arikan, 2001; Barney and Clark, 2007). 
Fourth, there must be organizational processes ("complementary resources and capabilities", such as formal reporting structure, management control systems, and compensation policies) organized to exploit the full competitive potential of these strategic (valuable, rare, inimitable) resources and capabilities. This is because neither the strategic resources and capabilities are likely to be a source of sustained competitive advantage by themselves, nor will the complementary resources and capabilities have the ability to generate sustained competitive advantage in isolation. Organizational processes, then, provide the fourth condition necessary for realizing sustained competitive advantage. In this theoretical model, the complementary resources and capabilities operate as an "adjustment factor" [emphasis added] (Barney, 1995; Barney and Arikan, 2001; Barney and Clark, 2007).

\section{iv) The path to competitive position}

Competitive advantage (CA) is defined as follows:

An enterprise has a Competitive Advantage if it is able to create more economic value than the marginal (breakeven) competitor in its product market... [In this respect,] the Economic Value created by an enterprise in the course of providing a good or service is the difference between the perceived benefits gained by the purchasers of the good and the economic cost to the enterprise. (Peteraf and Barney, 2003: 314)

For example, if the customers' maximum willingness-to-pay for a product/service is $£ 230$ /unit, and the total economic cost for this product/service is $£ 50 /$ unit, then the economic value created by the firm is (£230-£50) £180/unit (Barney, 2007; Peteraf and Barney, 2003). Figure 1 is an illustrative example for the basic components of CA.

[Insert Figure 1 here]

Considering the competitive position, three types of competitive advantage are identified: competitive disadvantage (CD); competitive parity (CP); and CA. First, the CD represents a 
situation in which "a firm creates less economic value than its rivals". In this respect, a sustained competitive disadvantage (SCD) indicates a CD that lasts a long time, and a temporary competitive disadvantage (TCD) indicates a CD that lasts a short time. Second, the CP represents a situation in which "a firm creates the same economic value as its rivals". Third, the CA represents a situation in which "a firm creates more economic value than its rivals". In this respect, a temporary competitive advantage (TCA) indicates a CA that lasts a short time, and a sustained competitive advantage (SCA) indicates a CA that lasts a long time (Barney, 2007). Figure 2 shows the different types of competitive positions.

[Insert Figure 2 here]

To this end, the theoretical model shows the characteristics of strategic resources and capabilities (as strategy inputs) and the different competitive advantages (as strategy objectives or outcomes). But, what about the different routes to CA? Four paths to CA have been identified as follows (Barney, 1991, 1995, 2007; Barney and Arikan, 2001; Barney and Clark, 2007; Barney and Wright, 1998):

First, a firm that exploits a worthless or irrelevant resource or capability (weakness) will not be able to choose and/or implement strategies that exploit environmental opportunities or neutralize threats. "Organizing to exploit this resource will increase the firm's costs or decrease its revenues". This generates less economic value than its rivals'. This below-normal performance implies a CD (temporary or sustained depending on how long it would last).

Second, a firm that exploits valuable but common resources when implementing a value creating strategy will create the same economic value as its rivals'. This normal performance 
implies a CP, which increases the firm's probability of economic survival, but does not involve CA.

Third, a firm that exploits valuable and rare but imitable resources when implementing value creating strategy will create more economic value than its rivals'. This above-normal performance implies a CA, or more precisely a TCA not SCA. That is because rivals will soon imitate the same strategy by acquiring the same resources to achieve the same position, resulting in $\mathrm{CP}$.

Finally, a firm that exploits valuable, rare, and inimitable resources when implementing value creating strategy will create more economic value than its rivals'. This above-normal performance implies a SCA. However, it is important here to mention to the nonsubstitutability assumption. If rivals cannot acquire the same resource, they will try to substitute it. In this respect, if a low number of rivals can substitute this resource to implement the same strategy, and this substitute is inimitable, then the focal firm will continue generating SCA. If, however, the substitute can be imitated, then the focal firm can generate a TCA that would be downgraded soon to $\mathrm{CP}$ when a large number of rivals imitate this substitute. Figure 3 depicts the VRIO framework of the RBV of the firm.

[Insert Figure 3 here]

This figure shows that, to implement a competitive strategy, a firm should efficiently and effectively organize business processes to exploit valuable, rare, and imperfectly imitable resources. By doing so, a large number of current and potential rivals cannot conceive of and/or implement the same strategy because of one or more of the three reasons stated under 
the inimitability attribute. Having shown an updated version of the RBV, we now turn to discuss the most critical criticisms of this strategic management view (or theory).

\section{VRIO: Thirteen criticisms}

Although the RBV is one of the most widely accepted theories within strategic management, it has also been the subject of significant criticism. There have been a few studies that have undertaken research to specifically examine whether the RBV framework satisfies key requirements for theoretical systems (e.g., Priem and Butler, (2001a, 2001b); Gibbert, 2006; Newbert et al., 2007; Sanchez, $(2008)^{6}$; Kraaijenbrinket al., 2010). That is, the degree to which the RBV presently possesses the explanatory and predictive power generally associated with theories, and if it is eligible to become a theory of $C A$. In addition, over the past twenty years there has been a wealth of literature utilizing and examining the RBV. Within this wide body of work there have been many misrepresentations of some influential works in this line of research, namely that of Penrose (1959), in our analysis of the literature we have specifically, where appropriate, quoted from and provided the original source.

We have analysed the literature for criticisms and have been able to identify thirteen separate reasons why the RBV does not adequately address the notion of resource-based competition. We have summarized these in Table 3 . The remainder of this section systematically examines these criticisms.

[Insert Table 3 here] 


\section{The value (V) conundrum (An exogenous black box)}

Sanchez (2008) argues that the VRIO framework fails to provide an adequate conceptual basis for identifying which organizational attributes (or "entities") can be considered as valuable resources. It offers no ideas of its own to show how such valuable resources can be identified. It should be noted, however, that the RIO dimensions of the theoretical framework have been argued not as the characteristics of a resource to be valuable, but as characteristics for the valuable resource to be a possible source of competitive advantage. In this regard, the RBV suggests that the traditional SWOT analysis or environmental models of competitive advantage would reveal which of those attributes constitute valuable resources that would help a firm exploit opportunities or neutralize threats, and which do not. Therefore, it "relies on 'outward in' analysis based on unspecified SWOT frameworks or 'environmental models' from industry structrual analysis, ["notably those advanced by Porter (1980, 1985)"], to identify what constitutues a [valuable] firm resouce and what does not". The SWOT analysis is itself an atheoretic mode of analysis that admits use of an unlimited range of approaches to analyzing strengths, weaknesses, opportunities, and threats - some of which may (and often do) lead to contradictory conclusions about what kinds of firm attributes constitute a strength or weakness, as well as what kinds of environmental situations constitute an opportunity or threat (Sanchez, 2008).

To conclude, by "outsourcing" a basic conceptual task for the previous strategy models, the VRIO framework fails to provide a systematic, consistent, and generally applicable basis for identifying the firm attributes that qualify as strategically valuable, and which firm attributes do not (Sanchez, 2008). In other words, “. . . the criteria for value in the RBV remain, at present, in an exogenous black box" (Priem and Butler, 2001a), "the external determination of value construct" (Priem and Butler, 2001b). Therefore, given the resulting Value 
Conundrum, from a scientific perspective, "the core proposition of the RBV is shown to be unwarranted theoretically, as well as being unimplementable in practice” (Sanchez, 2008).

\section{The uniqueness or rare (R) dilemma}

In the VRIO framework, the $R$ dimension means that a valuable resource should be rare (scarce or uncommon) to be a source of temporary competitive advantage. Sanchez (2008) argues that the use of rarity as an attribute for a valuable resource to be qulaified for generating competitive advantage gives rise to what might be called the "Uniqueness Dilemma". This occurs because firm resources are "heterogeneous" and thus at some level of analysis, all firm resources become unique, and thus rare. It is then logically impossible distinguish (even partially) resources that have the potential to be sources of competitive advantage from resources that do not. (Sanchez, 2008: 20). In other words, heterogeneity, as an assumption, eliminates the need for rarity, as an attribute.

In a similar vein, Hoopes et al. (2003) make an attempt to develop "a broad theory of competitive heterogeneity" to address "the RBV's inherent theoretical and empirical problems". In this respect, while reviewing the RBV, they argue that, as heterogeneity means that each firm has a unique bundle of resources, "of these three characteristics ["valuable, rare, isolated from imitation or substitution"], only value and inimitability are ultimately important. . . So concentrating on value and inimitability gets to the heart of the RBV".

Finally, Armstrong and Shimizu (2007) review 125 empirical RBV studies published in 8 leading journals between 1991 and 2005 to examine the key methodological issues related to the RBV theoretical framework. They identify rarity as a "potentially important" 
methodological issue. Though, in their sample, rarity is "scarcely discussed or examined". They therefore argue for theoretical modification or refinement of the RBV (Armstrong and Shimizu, 2007: 981-982).

\section{The cognitive impossibility dilemma (I)}

In the VRIO framework, the $I$ dimension assumes that a high level of causal ambiguity is required to sustain the COMPETITIVE ADVANTAGE. Barney and Clark (2007: 62) argue

that "both the firms that possess resources that generate a competitive advantage and firms that do not possess these resources, but seek to imitate them, must be faced with the same level of causal ambiguity". The argument here is that since some firm resources are tradable, competitors who know the resources that cause superior performance can buy or acquire these resources, and then imitate the same strategy. In other words, if managers are able to understand the relationship between the factor and the outcome, then this is sufficient to allow imitation or some other rapid response by rivals. This can be done through, for example, hiring "well-placed knowledgeable" managers in the superior performer, or engaging in a careful systematic study of this superior performer to reduce "knowledge disadvantage". If the causal ambiguity is low, and managers can understand the antecedents of the superior success, the valuable and rare resource cannot be a source of sustained competitive advantage, unless it is socially complex, and beyond the ability of firms to systematically manage and influence. Organisational culture is a case in point; here, the ability of rivals to imitate this resource is "significantly constrained".

Sanchez (2008) criticizes this reasoning (both the high level of causal amiguity and/or social complexity), and argues that it clearly contradicts the core proposition of the RBV that managers can engage in "resource-based strategizing" to create sustained competitive 
advantage. He also states that if one accepts this reaseoning, s/he must also accept that strategy researchers cannot manage to identify these resources. Furthermore, under the RBV logic, if one accepts this reasoning, then "the only explanation for past or future success in creating sustainable competitive advantage would have to be a firm's luck in acquiring or possessing such resources".

In this context, we need to distinguish between "know-what" and "know-how". The assumption that published data and/or knowledge articulated by insiders about, for example, R\&D capability, will "invoke rapid retaliatory responses by competitors . . . is overly simplistic". Know-what does not imply that "firm's competitors can duplicate or match the underlying inventive capability". Although know-what may help competitors in accelerating the innovation process, they still face much difficulty in imitating this capability due to the attributes of the accumulation process. On the other hand, the ability of rivals to replicate a distinctive capability rests on know-how not know-what. In this respect, much of the knowhow knowledge cannot be articulated, and the distinctive capability that is based on this tacit knowledge cannot be transferred (Levitas and Chi, 2002). This line of reasoning is developed further by Reed and DeFillippi (1990) who argue that "where ambiguity is so great that managers do not understand intra-firm causal relationships, . . . it may be impossible to utilize competencies for advantage".

Empirical research on the "linkage ambiguity" also supports this criticism. That is, despite the imitation pressures, lower linkage ambiguity among top and middle managers of the focal firm is associated with higher firm performance. Managers of superior performers clearly understand the link between competences and performance. This is particularly important because such understanding enable them to exploit, enhance, and redeploy sources of 
success. On the other hand, managers of the inferior performers do not clearly understand the link between resource factors and performance (King and Zeithaml, 2001).

\section{The organization $(O)$ dilemma}

The first version of the RBV, the VRIN framework, did not take into consideration the complementary resources and capabilities, the Organization (O) attribute. Due to a debate regarding the importance of such a type of resources in exploiting the VRI resources, the $O$ attribute has been added to the theoretical framework as an adjustment factor.

For example, the RBV argues that if some firms possess a valuable resource and the complementary resources and capabilities required to take full advantage of this valuable resource, they are expected to generate $\mathrm{CP}$. In this way, the RBV implicitly assumes that all these firms will efficiently and effectively organize business processes, in the same way, to exploit this valuable resource, and, as such, will produce the same result: $\mathrm{CP}$. This definitively goes against not only the other schools of thought, which Barney and Clark (2007) argue they share the same underlying theoretical structure, but also the RBV's assumption that firm resources are heterogeneous, (including the complementary resources and capabilities, and as such the competitive outcome would be different).

\section{The tautology problems}

A concensus conceptualization of the characteristics of a theory is: "theories are systematically related sets of statements, including some law-like generalizations, that are empirically testable. The purpose of theory is to increase scientific understanding through a systematized structure capable of both explaining and predicting phenomena" (Hunt, 1983: $10)$. 
Priem and Butler (2001a, 2001b) elaborate on the previous definition and examine if the fundamental statements in the VRIO framework (e.g., valuable and rare organizational resources can be a source of competitive advantage) meet the empirical content as a criterion that helps in separating "analytic statements" from "synthetic statements". The former is true by definition, and, therefore, a confrontation with data is not required to determine their correctness. As such, they have no empirical content. The latter, however, is not true by definition, and a confrontation with the real world must determine their correctness. As such, they have empirical content. When they replace the terms of the fundamental statements of the VRIO framework with their definitions in the theory, they find that the fundamental statements are true by definition, "self-verifying". Therefore, it is "not subject to disconfirmation", "tautological" statement". They conclude that:

Thus, Barney's definitions indicate that additional conceptual work is needed if the foundation of the RBV is to meet the law-like generalization standard. . . . [That is,] the characteristics ["valuable and rarity"] and outcomes ["competitive advantage"] must be conceptualized independently to produce a synthetic statement. (Priem and Butler, 2001a: 28)

Adopting a different view, Sanchez (2008) argues that the "tautology problem" in the identification of strategic resources is a fundamental problem of the VRIO framework that, due to the Value Conundrum, reduces "the RBV's core proposition to an essentially tautological proposition". He states that:

Empirical 'tests' of the RBV's core proposition commonly assert that resources identified ex post as being strategically valuable (by invoking some ad hoc environmental model or SWOT framework) were ipso facto the ex ante strategically valuable resources responsible for a firm's or firms' future success.

(Sanchez, 2008: 14)

To remedy this problem, researchers attempting to empirically test the core proposition of the RBV should identify, based on the characterization of what a valuable resource is, "ex ante the resources that will have strategic value ex post" (Sanchez, 2008). 


\section{The static problem}

The tautology problem as illustrated previously by Sanchez (2008) leads to the static prolem, also known as the ex post or equilibrium-based analysis. Amit and Schoemaker (1993) and Seoudi (2009) argue that most empirical studies in the RBV try to examine a firm's unique resources that explain some of the firm's past performance. In this respect, this ex post analysis may provide limited insight into the circumstances that will prevail in the future, taking into consideration the uncertainty about the economic and technological environments, competitors' behavior, and customer preferences.

Furthermore, Priem and Butler (2001a) state that "although the RBV began as a dynamic approach emphasizing change over time (e.g., Dierickx \& Cool, 1989; Penrose, 1959; Wernerfelt, 1984), much of the subsequent literature has been static in concept”. It offers just "a static argument". Though, "the static argument is descriptive: it identifies generic characteristics of rent-generating resources without much attention to differing situations or resource comparisons".

In other words, many authors argue that it does not adequately address the dynamic competitive environments. This is because it involves applying "a timeless equilibrium model to an inherently dynamic reality" (Black and Boal, 1994; Foss, 1996: 181; Hunt, 2001).

It should be noted, however, that such an equilibrium-based analysis was implicitly criticized a long time ago when discussing the "creative destruction" as the essence of "capitalism". In his seminal work, Schumpeter (1994: 84$)^{7}$ states that "the problem that is usually being visualized is how capitalism administers existing structures, whereas the relevant problem is how it creates and destroys them". It also has been criticized when discussing the self- 
transformation as the essence of "post-capitalist society". Drucker (1993) argues that, in the "knowledge society", organizations have to build systematic practices for managing a selftransformation.

As such, the equilibrium-based methodology of the RBV fails to capture important dynamic aspects such as knowledge creation, learning, and innovation (Seoudi, 2009; Spender, 1996). For example, the current conceptualization of the RBV fails to distinguish between: (1) knowledge integration (in the terminology of Grant (1996)) and knowledge creation (in the terminology of Nonaka and Takeuchi (1995)); (2) "exploitation of old certainties" and "exploration of new possibilities" (in the terminology of (March, 1991)); (3) "single-loop learning" and "double-loop learning" (in the terminology of Argyris (1999)), or "incremental learning" and "step function learning" (in the terminology of Helfat and Raubitschek (2000)). All have been argued to be essential characteristics of firms seeking to generate sustained competitive advantage.

\section{The absence of a chain of causality (Hierarchical schemata)}

As has been stated before, the VRIO framework classifies firm resources into four categories (capital, physical, human, organizational). Priem and Butler (2001a) describe this classification as "all-inclusive resources". Sanchez (2008) argues that this "ad hoc listing" of firm resources "adds nothing that is theoretically relevant in the characterization and analysis of resources". Similarly, while identifying some issues related to how to operationalise the RBV approach, Conner (1991) argues that consideration needs to be given to understanding the levels of resources that may exist within firms and to the potential contribution of each to performance differentials. This will help prevent everything in the firm from being labelled a resource and hence resources lose explanatory power. (Conner, 1991: 144-145) 
In addition, Madhavaram and Hunt (2008) argue that "classificational schemata are important for the development of theory, and hierarchical schemata are particularly important". In addition, they state that the conceptualization of capability and competence should not only address what the concept is, but also where the concept comes from. In this regard, Sanchez (2008) argues that, because of lacking any adequate conceptual basis for constructing such chains of causality, "the core proposition of the RBV is simply theoretically unjustified, and the RBV provides no actual basis for enacting the core proposition in practice".

\section{The asymmetry in assumptions regarding the strategic factor markets (SFMs)}

Many resource-based scholars recognize the work of Dierickx and Cool (1989a) as a significant theoretical contribution to the resource-based competition (e.g., Conner, 1991; Knott et al., 2003; Markides and Williamson, 1994; Peteraf, 1993; Priem and Butler, 2001a). The purpose of Dierickx and Cool's work is threefold: (1) to discuss some of the limitations inherent in the concept of SFM, a key concept in which the VRIO framework is grounded; (2) to put forward a complementary framework based on the notion of asset stock accumulation; and (3) to develop guidelines for assessing the sustainability of a firm's competitive adbvantage. Of particular importance here is the strong debate they raise against the SFM concept. They argue that SFMs are "incomplete", and "tradable assets" are not qualified to generate sustained competitive advantage. They question the assumption that all required assets by a firm can be bought and sold. They remind us that critical resources are accumulated rather than acquired, such as reputation for quality, dealer loyalty brand trust and R\&D capability. Thus, 'competitors who need an asset which is nontradable are constrained to 'building' it. . . Clearly, the assumption that factor markets are complete may not be pushed too far (Dierickx and Cool, 1989a: 105-109). 


\section{The accumulation of strategic resources (A black box)}

The second purpose of the Dierickx and Cool (1989a)'s work is to develop a process that takes into consideration the dynamic aspects of firm resources based on the notion of "asset stocks" and "asset flows". Their argument is simply that strategic asset stocks are accumulated over a period of time by following a consistent set of policies. For example, Toyota has developed a reputation for build quality by investing over a long period in production, quality control and training.

It is concluded from the debate between Barney (1989) and Dierickx and Cool (1989b) that the theoretical frameworks of the RBV (VRIN and VRIO) deliberately neglect the dynamic nature of strategic resources. As a result, many scholars argue that the VRIN and VRIO do not explicitly deal with the complex processes by which firms can endogenously accumulate and maintain all strategically valuable resources, namely that of intangible resources. Therefore, it does not address a critical challenge faced by practitioners while managing these resources, as the real source of competitive advantage (Priem and Butler, 2001a; Sanchez, 2008; Sanchez and Heene, 1997a; Seoudi, 2009).

In other words, a theory that draws solely on the SFM concept cannot take account of higherorder resources, capabilities and competences (Dierickx and Cool, 1989a; Makadok, 2001; Sanchez, 2008). It is a "resource-picking theory", rather than resource accumulating one (Makadok, 2001). Put differently, it is a theory that deals with "operand resources" rather than "operant resources" (in the terminology of Vargo and Lusch (2004)). While the former is important, the latter is the real source of competitive advantage (Dierickx and Cool, 1989a; Itami, 1987), especially that the degree of inimitability and the number of potential paths to 
competitive advantage increases as one moves from tradable resources to nontradable resources (Black and Boal, 1994).

\section{The synergetic effect of a bundle of resources (A black box)}

The third purpose of the Dierickx and Cool (1989a)'s work is to develop guidelines for assessing the sustainability of a firm's competitive advantage. They argue that the degree of imitablility of a particular asset stock is determined by "the interplay of a number of attributes" which may or may not characterize the process by which it may be accumulated. These are: "time compression diseconomies, asset mass efficiencies, interconnectedness of asset stocks, asset erosion, and causal [or linkage] ambiguity". Of particular importance is the attribute of "interconnectedness of asset stocks".

This attribute shows that none of the resources of a firm are capable of creating value on their own, but must be interrelated and coordinated with other resources through coherent firm processes that are capable of creating and producing successful products and/or services for markets (Madhavaram and Hunt, 2008; Penrose, 1959; Porter, 1991; Sanchez, 2008; Spender, 1994). Though, the VRIO framework treats resources as "singular distinct items rather than a bundle of resources" that gives a synergistic result (Black and Boal, 1994). It "characteristically overlooks the collective knowledge and skills required to coordinate the resources into a viable bundle. It overlooks, therefore, the synergistic aspects of the organization as a system of practice" (Spender, 1994: 353).

This criticism is reinforced by Priem and Butler (2001a) who state that "the processes through which particular resources provide competitive advantage remain in a black box .... 
We do not know, for example, how the resources generate sustainable rents, other than through their heterogeneity. Why is it that some heterogeneous resources generate value, whereas other heterogeneous resources do not?" What should be noted here is that, as Black and Boal (1994) argue, the value created, the degree of inimitability achieved, and the number of potential paths to competitive advantage increase as one moves from a single resource to a bundle of resources.

Although it is obvious from the discussion of the previous three criticisms $(8,9$, and 10$)$ that the resource-picking and capability-building mechanisms are complementary (and sometimes substitutes), the contribution of Dierickx and Cool (1989a) is unfortunately framed within the narrow focus of the VRIO theoretical framework. In other words, many scholars neglect: (1) the process by which strategic resources are accumulated and maintained; and (2) the way by which a bundle of resources is coordinated to give a synergistic result. By doing so, they neglect the dynamic nature of resource bundles.

\section{Unimplementable in practice}

Priem and Butler (2001a) argue that the VRIO framework is practicably unimplementable because it does not develop "meaningful management tools in the form of actionable prescriptions for practitioners". That is, a useful strategic management theory should provide prescriptions for both the independent variables ("Operational Validity") and outcome variables. VRIO does not. The practioner is unable to implement the action implementations of the theory or to manipulate the key independent variables. For example, precisely how is the practioner to go about obtaining rare and valuable resources that are hard to imitate and nonsubstitutable (Priem and Butler, 2001a: 31-32). 


\section{The epistemological impossibility problem}

Despite the previous criticisms, Sanchez (2008) argues that a scientific critique of the VRIO framework as a testable theory reveals the "epistemological impossibility problem". That is, the core proposition of the VRIO framework does not allow for "reproducibility of experiments", "falsifiability", and "generalizability".

Regarding the reproducibility of experiments:

Given that the core proposition of the RBV is that competitive advantage is a symptom of unique resources (firm heterogeneity) it is extremely difficult if not impossible to reproduce research conducted in one firm by finding a similar context in another (Sanchez, 2008: 29).

Regarding the falsifiability:

Given the broad notion of resources in the RBV it is always possible to identify a heterogeneous resource in a successful firm that can be argued to be the source of that firm's success. If to this we add the difficulty of recreating experiments in other firms, it is impossible to definitively reject the proposition that certain kinds of resources are the source of a firm's success (Sanchez, 2008: 29).

\section{Regarding the generalizability:}

Given the RBV's basic claim that a given firm's competitive success is the result of the firm's heterogeneous endowment of resources, this precludes any possibility of performing confirming experiments involving other firms that would be needed to support a generalized proposition, because other firms would have to have their own "heterogeneous" resource endowments (Sanchez, 2008: 29). 


\section{One framework for different competitive contexts}

Priem and Butler (2001a), Sanchez (2008), and Bowman and Collier (2006) criticize the level of generality the VRIO framework claims, and argue for developing "contingency approaches" or "middle-range strategy theories" that identify the competitive contexts within which these approaches are expected to hold ${ }^{8}$. That is, it is critical to establish boundaries for the framework by hypothesizing competitive contexts within which particular capabilities or competences are determined to be more or less valuable.

Sanchez (2008) argues that the competitive environments of firms may be fundamentally different in nature, and may span a spectrum from "stable (seen largely as a special case) to highly dynamic (regarded as an increasingly common if not dominant context)". Therefore, a "grand strategy theory" of universally applicable characterizations and derived prescriptions must take into consideration the qualitatively different kinds of competitive contexts. This leads to a further limitation. To take account of different competitive contexts and to develop universally applicable propositions may require such a high level of abstraction that they may lose any capacity for effectively addressing the specific conditions that distinguish qualitatively different competitive contexts (Sanchez, 2008: 49).

\section{The level of empirical support of the RBV}

Newbert (2007) conducts the first "systematic assessment of the RBV's level of empirical support". That is a sample of "RBV-grounded empirical articles", undertaken between 1994 and 2005, is analyzed in which four theoretical approaches are employed: (1) the "resource heterogeneity approach" (the VRIN framework); (2) the "organizing approach" (the VRIO framework); (3) the "conceptual-level approach"; and (4) the "dynamic capabilities 
approach" "The analysis shows that $91 \%$ of the total sample employs the resource heterogeneity approach. In this approach, the scholars argue on theoretical grounds that a given resource, capability, or core competence is valuable, rare, inimitable, and/or nonsubstitutable, quantify the amount of it possessed by a firm, and correlate this amount to some measure of competitive advantage or performance. The results show that while capabilities and core competencies do indeed contribute significantly to a firm's competitive advantage and/or performance, resources do not.

This is not surprising given that much of the foundational work on the RBV addresses the importance of deploying and not simply possessing resources. The more recent studies have . . . attempted to more precisely explain these processes. Newbert (2007) argues that future research should focus on the more contemporary theoretical extensions of RBV. Furthermore, Armstrong and Shimizu (2007) have suggested state that RBV research is at the stage of "interim struggles" (Weick, 1995: 385) through which the RBV can advance by further interaction between theoretical refinement and empirical development.

\section{Conclusions}

Our starting point for this study is a recognition that the field of research on resource based competition is full of nuanced terminology and misunderstandings. Of course, this partly reflects the intense interest and lively debate within the management research community, but it does nonetheless present difficulties for scholars attempting to begin research in the field. Furthermore, we also recognise that within this paradigm there exists a dominant theoretical framework- VIRO that we wished to examine. To address this two conceptual tasks have been undertaken here in this paper. 
First, this analysis structured the literature on resources-based competition into three distinct schools of thought. In doing this, we contribute to management research in two areas: i) to help the reader witness the deviation among the three schools of thought; ii) to help researchers work through the wide terminological confusion and situate their work within the relevant school of thought. Thus scholars should be aware of the basic organizational assumptions and interpretations that shape the three schools of thought. For example, those who are interested in specific phenomena, like radical innovations, are advised to adopt theories and approaches developed under the social constructionist school. Scholars who are interested in incremental innovations, on the other hand, are advised to adopt theories and approaches developed under the behavioural-evolutionary school.

Second, this study sought to draw together the criticisms that have emerged since Jay Barney wrote his widely known articles: "Strategic factor markets: Expectations, luck, and business strategy" (Barney, 1986); and "Firm resources and sustained competitive advantage" (Barney, 1991). Although much has been written on the subject in this time, very few have attempted to systematically draw together the criticisms that have emerged. This is particularly important as "major proponents of the RBV have been remarkably silent and occasionally evasive in responding to fundamental conceptual and theoretical criticisms" (Sanchez, 2008). Based on the thirteen criticisms and the low level of empirical support discussed above, we can conclude that the VRIO does not adequately address the notion of resource-based competition, and its claim to be a general view of resources is unwarranted theoretically and unsupported empirically. In other words, the generic attributes of rentgenerating resources (value, rare, imperfect imitability, and organization) should not be used to assess the sustainability of competitive advantage when the real source of this advantage is capabilities and competences. In this context, the other views (the dynamic capability- and 
competence-based views) have recognized that capabilities and competences in using resources are conceptually distinct from other kinds of firm resources. This has led to the identification of completely different attributes of rent-generating capabilities and competences (e.g., time compression diseconomies, asset mass efficiencies, interconnectedness of asset stocks, asset erosion, and/or or linkage ambiguity). We therefore suggest that researchers avoid the tendency to test a theoretical framework reflecting resource-picking mechanism when the real source of competitive success are capabilities and competences, which, unsurprisingly enjoy a high level of empirical support.

The extensive attention granted to the RBV may be explained by one or more of the following. First, "the relative ease of measuring resources as compared to (dynamic) capabilities and (core) competencies". Second, the theoretical framework of the RBV is widely regarded as "the first formalization of the then-fragmented resource-based literature into a comprehensive (and thus) empirically testable theoretical framework" (Newbert, 2007), taking into consideration the nature of the early versions of the alternative views (practitioner-oriented and diversification-emphasized: e.g. Prahalad and Hamel, 1990). Third, "the management-fashion-setting process" may also explain why some scholars have elevated it from a view to theory (Abrahamson, 1996). Fourth, neglecting (and, and in some cases, misinterpreting) the classic scholary work (e.g., Penrose (1959) and Dierickx and Cool (1989a)) may also explain why the VRIO framework has been elevated from a view (within this paradigm) to a theory (codifing the whole paradigm), and why it has receievd so much attention. 


\section{References}

Abrahamson, E. (1996). Management Fashion. Academy of Management Review, 21(1), 254-285.

Ambrosini, V., and Bowman, C. (2009). What are dynamic capabilities and are they a useful construct in strategic management? International Journal of Management Reviews, 11(1), 29-49.

Amit, R., and Schoemaker, P. J. H. (1993). Strategic assets and organizational rent. Strategic Management Journal, 14(1), 33-46.

Argyris, C. (1999). On organizational learning (2nd ed.). Oxford: Blackwell Business.

Armstrong, C. E., and Shimizu, K. (2007). A review of approaches to empirical research on the resource-based view of the firm. Journal of Management, 33(6), 959-986.

Barney, J. B. (1986). Strategic factor markets: Expectations, luck, and business strategy. Management Science, 32(10), 1231-1241.

Barney, J. B. (1989). Asset stock and sustained competitive advantage: A comment. Management Science, 35(12), 1511-1513.

Barney, J. B. (1991). Firm resources and sustained competitive advantage. Journal of Management, 17(1), 99.

Barney, J. B. (1995). Looking inside for competitive advantage. Academy of Management Executive, 9(4), 49-61.

Barney, J. B. (2007). Gaining and sustaining competitive advantage (3rd ed.). Upper Saddle River, NJ: Pearson Prentice Hall.

Barney, J. B., and Arikan, A. M. (2001). The resource-based view: Origins and implications. In M. A. Hitt, R. E. Freeman and J. S. Harrison (Eds.), The Blackwell handbook of strategic management. Oxford: Blackwell Business.

Barney, J. B., and Clark, D. N. (2007). Resource-based theory: Creating and sustaining competitive advantage. Oxford: Oxford University Press.

Barney, J. B., and Wright, P. M. (1998). On becoming a strategic partner: The role of human resources in gaining competitive advantage. Human Resource Management, 37(1), 31-46.

Black, J. A., and Boal, K. B. (1994). Strategic resources: Traits, configurations and paths to sustainable competitive advantage. Strategic Management Journal, 15(S2), 131-148.

Bowman, C., and Collier, N. (2006). A contingency approach to resource-creation processes. International Journal of Management Reviews, 8(4), 191-211. doi: 10.1111/j.14682370.2006.00127.x

Collis, D. J., and Montgomery, C. A. (1995). Competing on resources: Strategy in the 1990s. Harvard Business Review, 73(4), 118-128.

Conner, K. R. (1991). A historical comparison of resource-based theory and five schools of thought within industrial organization economics: Do we have a new theory of the firm? Journal of Management, 17(1), 121.

Daft, R. L., and Weick, K. E. (1984). Toward a model of organizations as interpretation systems. Academy of Management Review, 9(2), 284-295.

Dierickx, I., and Cool, K. (1989a). Asset stock accumulation and sustainability of competitive advantage. Management Science, 35(12), 1504-1511.

Dierickx, I., and Cool, K. (1989b). Asset stock accumulation and the sustainability of competitive advantage: Reply. Management Science, 35(12), 1514-1514.

Drucker, P. F. (1993). Post-capitalist society. Oxford: Butterworth-Heinemann.

Foss, N. J. (1996). Whither the competence perspective? In N. J. Foss and C. Knudsen (Eds.), Towards a competence theory of the firm. London: Routledge.

Grant, R. M. (1996). Toward a knowledge-based theory of the firm. Strategic Management Journal, 17(Winter Special Issue), 109-122.

Hamel, G., and Heene, A. (Eds.). (1994). Competence-based competition: Wiley.

Hamel, G., and Prahalad, C. K. (1989). Strategic intent. Harvard Business Review, 67(3), 63-78.

Helfat, C. E., and Raubitschek, R. S. (2000). Product sequencing: Co-evolution of knowledge, capabilities and products. Strategic Management Journal, 21(10-11), 961-979.

Hoopes, D. G., Madsen, T. L., and Walker, G. (2003). Why is there a resource-based view? Toward a theory of competitive heterogeneity. Strategic Management Journal, 24(10), 889-902. 
Hunt, S. D. (1983). General theories and the fundamental explananda of marketing. Journal of Marketing, 47(4), 9-17.

Hunt, S. D. (2001). Commentary - A general theory of competition: Issues, answers and an invitation. European Journal of Marketing, 35(5/6), 524-548.

Hunt, S. D., and Derozier, C. (2004). The normative imperatives of business and marketing strategy: Grounding strategy in resource-advantage theory. Journal of Business \& Industrial Marketing, 19(1), 5-22.

Hunt, S. D., and Morgan, R. M. (1995). The comparative advantage theory of competition. Journal of Marketing, 59(2), 1.

Hunt, S. D., and Morgan, R. M. (1996). The resource-advantage theory of competition: Dynamics, path dependencies, and evolutionary dimensions. Journal of Marketing, 60, 107-114.

Hunt, S. D., and Morgan, R. M. (1997). Resource-advantage theory: A snake swallowing its tail or a general theory of competition? Journal of Marketing, 61(4), 74.

Itami, H. (1987). Mobilizing invisible assets. Cambridge, MA: Harvard University Press.

King, A. W., and Zeithaml, C. P. (2001). Competencies and firm performance: Examining the causal ambiguity paradox. Strategic Management Journal, 22(1), 75-99.

Knott, A. M., Bryce, D. J., and Posen, H. E. (2003). On the strategic accumulation of intangible assets. Organization Science, 14(2), 192-207.

Levitas, E., and Chi, T. (2002). Rethinking Rouse and Daellenbach's rethinking: Isolating vs. testing for sources of sustainable competitive advantage. Strategic Management Journal, 23(10), 957-962.

Lockett, A., Thompson, S., and Morgenstern, U. (2009). The development of the resource-based view of the firm: A critical appraisal. International Journal of Management Reviews, 11(1), 9-28.

Madhavaram, S., and Hunt, S. (2008). The service-dominant logic and a hierarchy of operant resources: Developing masterful operant resources and implications for marketing strategy. Journal of the Academy of Marketing Science, 36, 67-82.

Makadok, R. (2001). Toward a synthesis of the resource-based and dynamic-capability views of rent creation. Strategic Management Journal, 22(5), 387-401.

March, J. G. (1991). Exploration and exploitation in organizational learning. Organization Science, $2(1), 71-87$.

Markides, C. C., and Williamson, P. J. (1994). Related diversification, core competences and corporate performance. Strategic Management Journal, 15, 149-165.

Mellahi, K., and Sminia, H. (2009). Guest Editors' Introduction: The frontiers of strategic management research. International Journal of Management Reviews, 11(1), 1-7.

Miles, R. E., Snow, C. C., Meyer, A. D., and Coleman, J. H. J. (1978). Organizational strategy, structure, and process. Academy of Management Review, 3(3), 546-562.

Nelson, R. R., and Winter, S. G. (1982). An evolutionary theory of economic change. Cambridge, Mass.; London: Belknap Press.

Newbert, S. L. (2007). Empirical research on the resource-based view of the firm: An assessment and suggestions for future research. Strategic Management Journal, 28(2), 121-146.

Nonaka, I., and Takeuchi, H. (1995). The Knowledge-creating company: How Japanese companies create the dynamics of innovation. New York; Oxford: Oxford University Press.

Penrose, E. T. (1959). The theory of the growth of the firm. New York: Wiley.

Peteraf, M. A. (1993). The cornerstones of competitive advantage: A resource-based view. Strategic Management Journal, 14(3), 179-191.

Peteraf, M. A., and Barney, J. B. (2003). Unraveling the resource-based tangle. Managerial and Decision Economics, 24(4), 309-323.

Porter, M. E. (1980). Competitive strategy: Techniques for analyzing industries and competitors. New York: Free Press.

Porter, M. E. (1991). Towards a dynamic theory of strategy. Strategic Management Journal, 12(S2), 95-117.

Prahalad, C. K., and Hamel, G. (1990). The core competence of the corporation. Harvard Business Review, 68, 79-91.

Priem, R. L., and Butler, J. E. (2001a). Is the resource-based "view" a useful perspective for strategic management research? Academy of Management Review, 26, 22-40. 
Priem, R. L., and Butler, J. E. (2001b). Tautology in the resource-based view and the implications of externally determined resource value: Further comments. Academy of Management Review, 26(1), 57-66.

Reed, R., and DeFillippi, R. J. (1990). Causal ambiguity, barriers to imitation, and sustainable competitive advantage. Academy of Management Review, 15, 88-102.

Rumelt, R. P. (1984). Towards a strategic theory of the firm. In R. B. Lamb (Ed.), Competitive strategic management. Englewood Cliffs ; London: Prentice-Hall.

Rumelt, R. P. (1991). How much does industry matter? Strategic Management Journal, 12(3), 167185.

Sanchez, R. (2008). A scientific critique of the resource-base view (RBV) in strategy theory, with competence-based remedies for the RBV's conceptual deficiencies and logic problems. In R. Sanchez (Ed.), Fundamental issues in competence theory development (Research in competence-based management) (Vol. 4, pp. 3-78): Emerald Group Publishing Limited.

Sanchez, R., and Heene, A. (1997a). Competence-based strategic management: Concepts and issues for theory, research, and practice. In A. Heene and R. Sanchez (Eds.), Competence-based strategic management. Chichester: Wiley.

Sanchez, R., and Heene, A. (2004). The new strategic management: Organization, competition and competence. New York; [London]: Wiley.

Sanchez, R., and Heene, A. (Eds.). (1997b). Competence-based strategic management. Chichester: Wiley.

Sanchez, R., Heene, A., and Thomas, H. (1996a). Introduction: Toward the theory and practice of competence-based competition. In R. Sanchez, A. Heene and H. Thomas (Eds.), Dynamics of competence-based competition: Theory and practice in the new strategic management. Oxford: Pergamon.

Sanchez, R., Heene, A., and Thomas, H. (Eds.). (1996b). Dynamics of competence-based competition: Theory and practice in the new strategic management. Oxford: Pergamon.

Schumpeter, J. A. (1994). Capitalism, socialism and democracy (5th ed.). London: Routledge.

Seoudi, I. (2009). The resource-capability-competence perspective in strategic management: A reappraisal of the epistemological \& theoretical foundations. Published $\mathrm{PhD}$ Thesis, Department of Economics, School of Graduate Studeis, Case Western Reserve University.

Spender, J. C. (1994). Organizational knowledge, collective practice and Penrose rents. International Business Review, 3(4), 353-367.

Spender, J. C. (1996). Making knowledge the basis of a dynamic theory of the firm. Strategic management journal, 17(Winter Special), 45-62.

Teece, D. J., Pisano, G., and Shuen, A. (1997). Dynamic capabilities and strategic management. Strategic Management Journal, 18, 509-533.

Vargo, S. L., and Lusch, R. F. (2004). Evolving to a new dominant logic for marketing. Journal of Marketing, 68(1), 1-17.

Wang, C. L., and Ahmed, P. K. (2007). Dynamic capabilities: A review and research agenda. International Journal of Management Reviews, 9(1), 31-51. doi: 10.1111/j.14682370.2007.00201.x

Wernerfelt, B. (1984). A resource-based view of the firm. Strategic Management Journal, 5(2), 171180.

Wernerfelt, B. (1995). The resource-based view of the firm: Ten years after. Strategic Management Journal, 16(3), 171-174.

Winter, S. G. (2003). Understanding dynamic capabilities. Strategic Management Journal, 24(10), 991-995.

\section{Notes}

1. In this paradigm, strategy may be known as "industry-based strategy". The structure of this paradigm may be presented in the following three levels. First, strategy should focus on choosing an attractive industry and/or altering the structure of the chosen industry to increase monopoly power. In this regard, the profitability of a firm in an industry is determined by the five competitive forces identified by Porter (1980). Second, after choosing an attractive industry or altering the industry structure, the firm should choose among the three generic strategies. In this regard, the firm "must make a choice among them, or it will become stuck in the 
middle". Third, internal factors come into play after choosing one of the three generic strategies. That is, the firm should manage well the activities in its "value chain", which are considered as the basic unit in competitive advantage (Hunt and Derozier, 2004). In this regard, the "value chain" analysis is considered as an "accepted" alternative for both the RBV and the (SW) of SWOT analysis (Priem and Butler, 2001b).

2. The active creator of environment is more akin to the "Prospector" (in the terminology of Miles et al. (1978)) and the "enacting organization" (in the terminology of Daft and Weick (1984)).

3. In 1994, the work of Wernerfelt (1984), A resource-based view of the firm, was awarded annual prize for the "best paper" published in the Strategic Management Journal five or more years prior (Wernerfelt, 1995).

4. Barney (1986) introduces the concept of strategic factor markets to: (1) show that all strategic factors required to implement strategies can be traded in these markets; (2) argue that both the costs of the strategic factors required to implement strategies and the future returns expected from these strategies should be taken into consideration; (3) argue that a firm can generate above-normal economic performance if it is able to create imperfection in the strategic factor market; (4) argue that a firm can "become consistently better informed about the value of strategies they are implementing than other firms" ("systematic expectional advantage") by "turning inwardly" to analyze its resources and capabilities; and (5) conclude that "the search for CA and superior financial performance must begin with an analysis of the resources and capabilities a firm currently control".

5. Resources that do not enable a firm to conceive of and/or implement strategies that improve its efficiency and effectiveness or that have no impact on the firm's strategizing processes are considered worthless resources (Barney, 1991).

6. Sanchez (2008: 1-2) "applies the principles of the philosophy of science and the derived scientific method to analyze the foundational concepts and core proposition of the RBV" (both the VRIN and VRIO) framework, and identifies "seven fundamental conceptual deficiencies and logic problems".

7. The book was first published in the USA in 1942.

8. This notion can be easily seen in the work of Miles et al. (1978). They develop a typology for organizational strategies according to three "product-market domains". That is, the prospector strategy is more relevant for the domain that is broad and in a continuous state of development; the defender strategy is more relevant to the domain that is narrow and stable; and the analyzer strategy is more relevant to the hybrid domain.

9. The first two approaches seek to identify the actual resource and capability that confer an advantage to a firm. The third approach seeks to test whether the attributes (valuable, rare, inimitable), as essential for a resource to effectively contribute to a firm's advantage, are indeed significant predictors to this end. The last approach seeks to test the effect of the interaction of a specific resource (that has the four attributes of the VRIN or the VRIO) and a dynamic capability on a firm's advantage. 